\title{
Blood Lymphocyte Count Following the Ligation of the Thoracic Duct in Man ${ }^{1)}$
}

\author{
By \\ Kazuhiko Awaya, Akiho Inada, Yasunori Tanaka, \\ and Tokiichi Kuwahara \\ Department of Anatomy, Yamaguchi Medical School, Ube \\ (Director: Prof. Bunsuke Osogoe)
}

As reported by many workers (Bied 1 and von Decastello, 1901 ; $\mathrm{D}$ avis and $\mathrm{C}$ ar Is o n, 1909-1910; $\mathrm{B} u \mathrm{nting}$ and $\mathrm{Hu}$ s to n, 1921; Lee, 1922; B la lock et al., 1937; $\mathrm{M}$ a $\mathrm{n} \mathrm{n}$ and $\mathrm{Hig}$ i in s, 1950 ; $\mathrm{Hughes}$ et al., 1956; $\mathrm{H}$ a n s e $\mathrm{n}, 1958$ ), the lymphocytes in the peripheral blood markedly decrease in number either upon ligation of the thoracic or right lymph duct, or upon canulation of these lymph vessels to drain the lymph off.

Accordingly, it is beyond any doubt that the majority of the lymphocytes in the circulating blood reached the blood stream through the thoracic and right lymph ducts. However, such observations have so far been made mostly on experimental animals such as dogs, cats, rabbits or rats, and very few has been made on human subjects, for no ligation of the thoracic duct can be made in healthy people; it may be conducted only in such a special case as the chylothorax caused by a break of the thoracic duct (Goorwit c h, 1955; M a u r e r, 1956).

In the literature, therefore, there are no reliable data on the changes in the number of lymphocytes in the circulating blood in man following the ligation of the thoracic duct.

Recently we have had an opportunity to obtain two cases of the ligation of human thoracic duct in operations performed in the Second Surgical Division of this Medical School. In these instances, the cerebrospinal fluid has been drained into the thoracic duct of

1) Supported in part by a grant to Professor Bunsuke Osog o e from the Ministry of Education (Grant-in-Aid for Fundamental Scientific Research, Cooperative). 
the patients suffering from hydrocephalus internus. In this paper we wish to present, with some comments, the results of our observations made on the number of lymphocytes in the peripheral blood of these patients before, and during a period of more than one year following, the thoracic duct ligation. The detailed case report and the method of operation has been published elsewhere by Y o k o y $\mathrm{m}$ a et al. (1959).

\section{Case Report}

The ligation of the thoracic duct was conducted as the operation required for lowering the intracranial pressure by draining the cerebrospinal fluid of the patients with hydrocephalus internus into the thoracic duct. Following a right thoracotomia made at the level of the $8 \mathrm{th}$ intercostal space, about $1 \mathrm{~cm}$ length of the thoracic duct was cut off at the height of the 9 th thoracal vertebra, and the distal end of the duct were ligated. Then one end of a polyvinyl tubing was inserted into the lateral ventricle of the brain by a craniotomia and fixed on adjacent periosteum. The other end of the tubing was introduced into the pleural cavity through the postcranial and dorsal subcutaneous tissues, inserted into the proximal end of the cut thoracic duct and fixed there. The part of the polyvinyl tubing residing in the pleural cavity was fixed on the paravertebral tissue or periosteum of an adjacent rib. As the thoracic duct was ligated at the cranial side of the diaphragm at the height of the 9 th thoracal vertebra, the pathway of the lymph and lymphocytes which had found their way into the blood through the thoracic duct was now blocked. On two patients undergoing such an operation, the change in the percentage and the absolute number of the peripheral blood lymphocytes was followed before and after the ligation of the thoracic duct.

Case 1. Male, 54 years old; underwent the above-mentioned operation because of the heightened intracranial pressure following the extirpation of a meningioma in the right posterior fossa. The results of the lymphocyte counts before and after the ligation of the thoracic duct of this patient are given in Table 1 and Figs. 1 and 2. The percentage of the lymphocytes, which showed a relatively high values of $48.5,48.5$, and $49 \%$ on 3 examinations made before the ligation, dropped down to $20.0 \%$ immediately after ligation. This was further followed by low values like 17.6, 5.5, 9.5, 
Table 1. Changes in the blood lymphocyte count after ligation of thoracic duct of a 54-year-old man, who underwent a shunting operation for hydrocephalus to drain cerebrospinal fluid into thoracic duct.

\begin{tabular}{|c|c|c|c|c|}
\hline \multirow{2}{*}{\multicolumn{2}{|c|}{ Time interval }} & \multirow{2}{*}{$\begin{array}{l}\text { Total number } \\
\text { of leukocytes }\end{array}$} & \multicolumn{2}{|c|}{ Lymphocytes } \\
\hline & & & $\begin{array}{l}\text { Differential } \\
\text { count }(\%)\end{array}$ & Absolute number \\
\hline \multirow{3}{*}{\multicolumn{2}{|c|}{ Before ligation }} & 14,800 & 49.0 & 7,252 \\
\hline & & 13,400 & 48.5 & 6,499 \\
\hline & & 7,600 & 48.5 & 3,686 \\
\hline $\begin{array}{r}\text { Immedia } \\
\text { ligat }\end{array}$ & $\begin{array}{l}\text { tely after } \\
\text { ion }\end{array}$ & 13,000 & 20.0 & 2,600 \\
\hline & our & 21,400 & 17.0 & 3,638 \\
\hline & ours & 20,600 & 5.5 & 1,133 \\
\hline 4 & $"$ & 23,600 & 9.5 & 2,185 \\
\hline 12 & $"$ & 17,000 & 12.0 & 2,040 \\
\hline 1 & & 13,600 & 19.0 & 2,584 \\
\hline & ays & 7,600 & 26.0 & 1,980 \\
\hline 3 & $"$ & 7,000 & 25.5 & 1,785 \\
\hline 5 & $"$ & 10,400 & 29.5 & 3,016 \\
\hline 7 & $"$ & 12,200 & 27.0 & 3,294 \\
\hline 10 & $"$ & 12,400 & 26.0 & 3,224 \\
\hline 14 & $"$ & 9,400 & 13. 0 & 1,222 \\
\hline & veeks & 7,800 & 29.0 & 2,262 \\
\hline 4 & $"$ & 10,200 & 19.0 & 1,938 \\
\hline 5 & $"$ & 7,200 & 37.0 & 2,664 \\
\hline 6 & $"$ & 7,400 & 35.0 & 2,590 \\
\hline 8 & $"$ & 14,600 & 30.0 & 4,380 \\
\hline 9 & $"$ & 6,100 & 30.0 & 1,830 \\
\hline 10 & $"$ & 9,000 & 25.0 & 2,250 \\
\hline 11 & $"$ & 16,600 & 10.0 & 1,660 \\
\hline 12 & $"$ & 19,200 & 16.0 & 3,072 \\
\hline 14 & $"$ & 11,000 & 26.0 & 2,860 \\
\hline 15 & $"$ & 11,600 & 26.0 & 3,016 \\
\hline 70 & $"$ & 7,400 & 40.5 & 3,432 \\
\hline
\end{tabular}

and $12.0 \% 1,2,4$, and 12 hours after the ligation, respectively. $\therefore$ Thereafter, it tended to increase slightly, and reached relatively high values of $37 \%$ at the 70 th week. However, it showed a considerable fluctuation on consecutive examinations, and ultimately failed to attain the value obtained before the ligation.

As regards the absolute number of the lymphocytes, it fluctuat...ed over a relatively wide range like $3,700,6,500,7.250$ on 3 exami- 


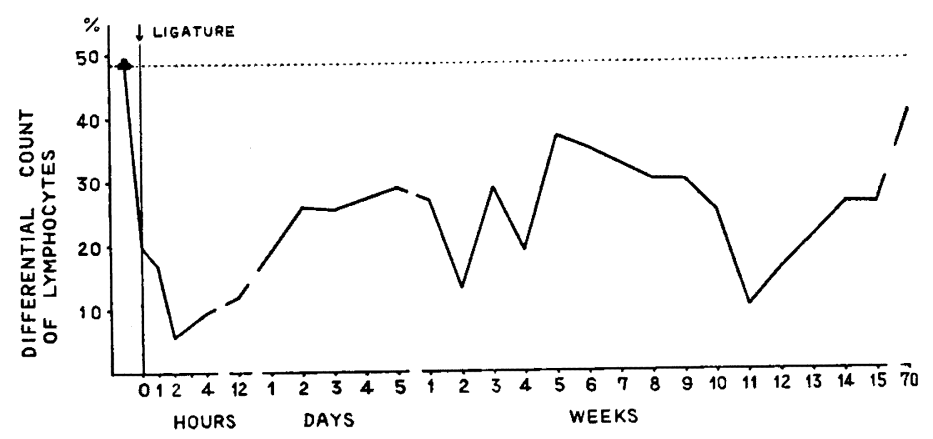

Fig. 1. Changes in the differential count of lymphocytes after ligation of thoracic duct.

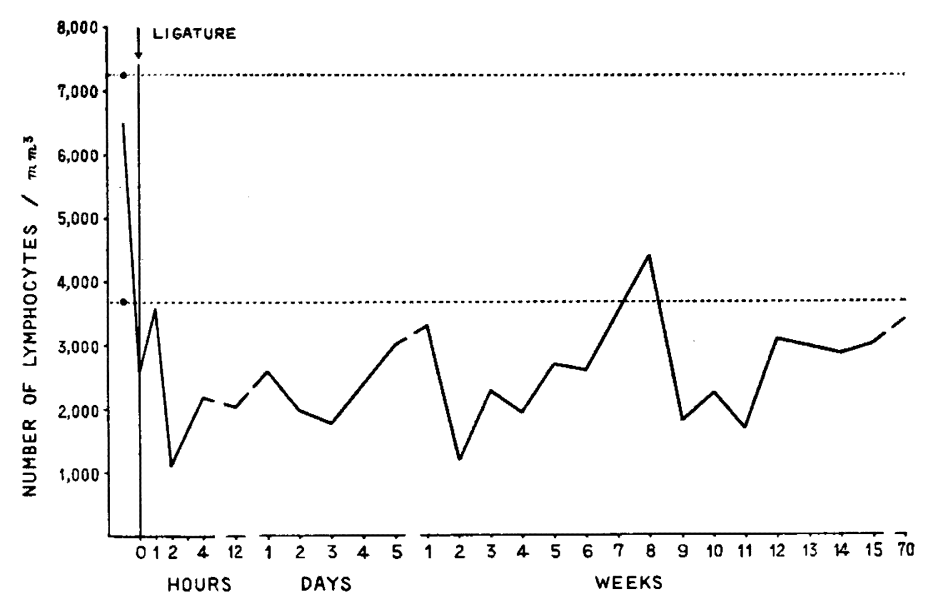

Fig. 2. Changes in the lymphocyte count (absolute number) after ligation of thoracic duct.

nations prior to the ligation. It started to decrease, from immediately after the ligation onward, and reached a low value of 1,1312 hours after the ligation. Until 24 hours after the ligation, the absolute number of the lymphocytes was maintained as less than 2,500 , in spite of a remarkable increase in the number of leukocytes $(13,600-23,600)$. It tended to increase slowly starting from the 3rd day, and, after a temporal approach to the lowest value observed before the ligation on the 8th day, it underwent a decline and a rise which repeated twice. It failed, however, to reach or surpass the lowest value observed before the ligation even on the 70th week. 
Case 2. Female, 29 years old; underwent the above-mentioned operation because of the hydrocephalus internus due to the blockade of the aqueduct of the midbrain caused by the gliosis. Results of the observations made on this subject are listed in Table 2. In this instance also, both percentage and absolute number of lym-

Table 2. Changes in the blood lymphocyte count after ligation of thoracic duct of a 29-year-old woman, who underwent a shunting operation for hydrocephalus to drain cerebrospinal fluid into thoracic duct and died on the 10th day after operation.

\begin{tabular}{|c|c|c|c|}
\hline \multirow{2}{*}{ Time interval } & \multirow{2}{*}{$\begin{array}{l}\text { Total number } \\
\text { of leukocytes }\end{array}$} & \multicolumn{2}{|c|}{ Lymphocytes } \\
\hline & & $\begin{array}{l}\text { Differential } \\
\text { count }(\%)\end{array}$ & Absolute number \\
\hline Before ligation & 6,800 & 36.6 & 2,468 \\
\hline 2 hours after ligation & 8,200 & 11.0 & 900 \\
\hline 6 hours & 9,000 & 9.0 & 810 \\
\hline $8 \quad$ & 10,800 & 12.0 & 1,296 \\
\hline 12 hours & 10,400 & 11.0 & 1,140 \\
\hline 1 day & 17,200 & 15.0 & 2,580 \\
\hline 2 days & 10,800 & 14.0 & 1,510 \\
\hline $3 \quad$ & 13,400 & 13.0 & 1,740 \\
\hline $5 \quad$ & 14,400 & 14.0 & 2,020 \\
\hline $7 "$ & 13,100 & 20.0 & 2,620 \\
\hline $10 "$ & 21,700 & 10.0 & 2,170 \\
\hline
\end{tabular}

phocytes showed a marked decrease throughout the period from immediately after the ligation of the thoracic duct to the death on the 10th day, the most remarkable lymphopenia being noted 2 to 12 hours after ligation.

\section{Discussion}

From what has been described of the above two cases, it can be stated that the consequence of the thoracic duct ligation revealed itself most strongly during the period of 12 hours immediately following the ligation, when percentage as well as absolute number of lymphocytes were diminished quite markedly. Beyond this critical period there was a trend of gradual recovery, but for more than 1 year in Case 1 and until the 10th day when the death took place in Case 2, the number of lymphocytes remained lower than the lowest value obtained before ligation. 


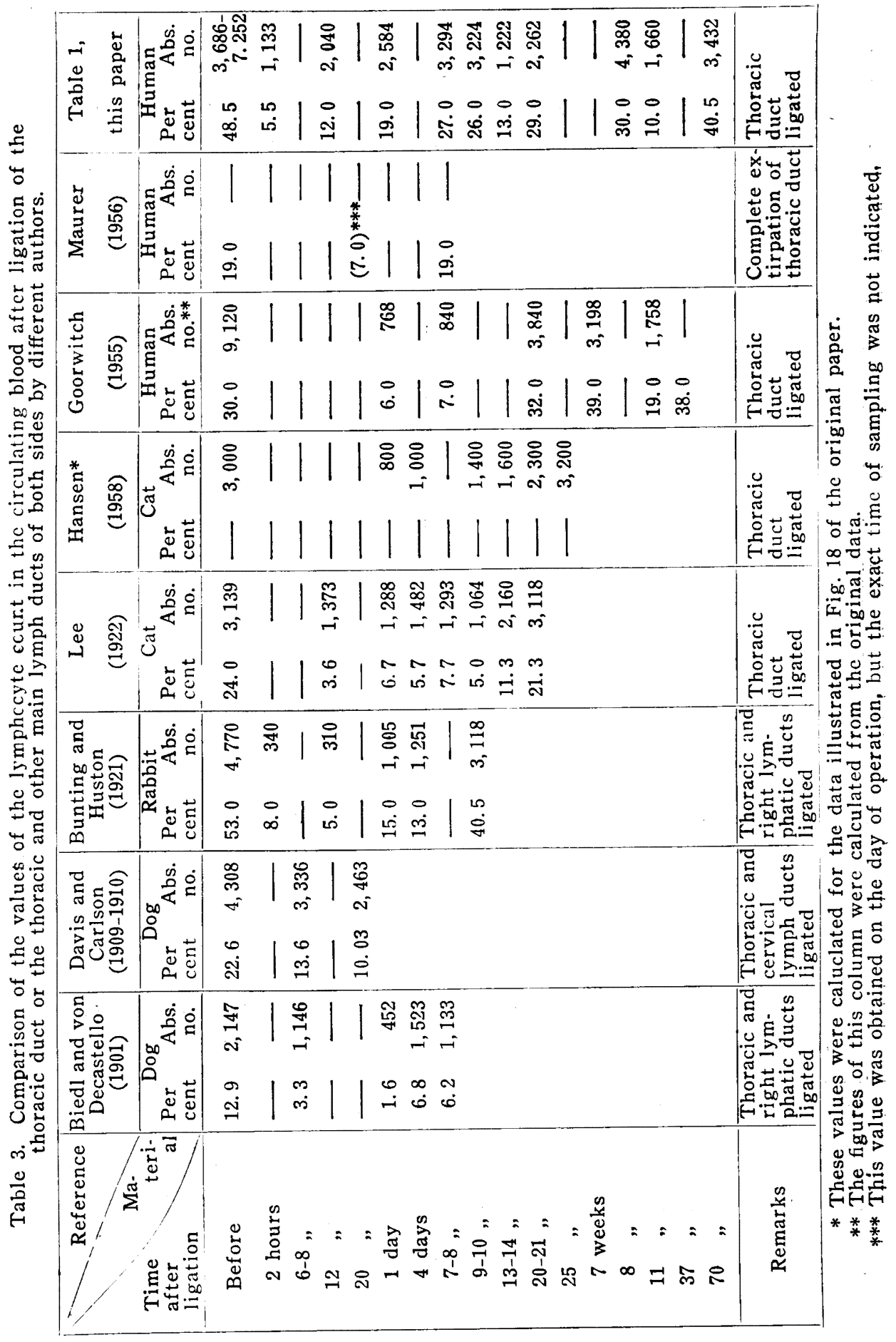


As regards the literature on the changes in the number of lymphocytes in the peripheral blood following the ligation of the thoracic duct, there are several reports on the remarkable lymphopenia, which however disappeared around the third week, after the ligation of the thoracic (or thoracic and right lymph) ducts in several experimental animals like rabbits, dogs and cats. Goorwitz (1955) observed a recovery of the percentage of peripheral blood lymphocytes up to the preoperative level during the third week following a clinical ligation of the thoracic duct conducted in a 44-year-old woman suffering from chylothorax caused by an external lesion. Also, M a u re $\mathrm{r}$ (1956) reported a case in which the lymphocyte percentage in peripheral blood returned to the normal value on the 8th day after extirpation of thoracic duct in a 37year-old woman with a benign tumor producing spontaneous chylothorax. Because of the lack of a detailed observation during 24 hours following the ligation or removal of the thoracic duct in these instances, it is not known whether there actually occurred a lymphopenia at all. The comparison of the results of the above workers with the ones obtained in the present study is compiled in Table 3. As was first observed here, a rapid decrease in the number of lymphocytes in the circulating blood following a thoracic duct ligation in human beings indicates that the majority of the lymphocytes in the circulating blood is transported into the blood stream by way of the thoracic duct. In addition, the trend of a relatively early recovery from the severe lymphopenia which rapidly appeared upon ligation of the thoracic duct suggests an early formation of alternative lymphatic pathway.

\section{Summary}

1. In order to drain the cerebrospinal fluid into the thoracic duct in patients suffering from hydrocephalus internus, operations were conducted in which the thoracic duct was cut off $1 \mathrm{~cm}$ long at the level of the 9th thoracal vertebra under a right thoracotomia, the distal end of the duct being ligated while the proximal end connected with a polyvinyl tubing with the lateral ventricle. On two patients with the thoracic duct ligated, observations were made of the pre- and post-operative changes in the number of $1 \mathrm{ym}$ phocytes in the peripheral blood.

2. In Case 1 (54-year-old, male), the percentage and absolute 
number of lymphocytes in peripheral blood decreased markedly during the period of 2 to 12 hours after the ligation of the thoracic duct. Thereafter the sign of a relatively early recovery was obtained, but the lymphocyte count was maintained at a level inferior to the lowest value obtained prior to the ligation throughout a period of 70 weeks.

3. In Case 2 (29-year-old, female), the patient died on the 10 th day after operation; the percentage and absolute number of lymphocytes in the peripheral blood decreased remarkably during the 2nd to 12 th hours after the ligation of the thoracic duct, a marked lymphopenia persisting until the 10th day on which the patient died.

4. The observations made on the human lymphopenia caused by the thoracic duct ligation are in a fairly good agreement with the ones reported by previous workers on the experimental animals, indicating that the majority of the lymphocytes in the circulating blood is transported into the blood stream by way of the thoracic duct. In addition, the trend of a relatively rapid recovery from the lymphopenia caused by the thoracic duct ligation suggests an early formation of alternative lymphatic pathway.

\section{References}

$\mathrm{B}$ i e d l, A. and A. von D e c a s t el 1 o 1901. Über Änderungen des Blutbildes nach Unterbrechung des Lymphzuflusses. Pflüg. Arch. ges. Physiol., 86 : 259-290.

Blalock, A., C.S. Robinson, R.S. Cunningham and M. E. Gray 1937. Experimental studies on lymphatic blockage. Arch. Surg., 34: 1049-1071.

Bunting, C. H. and J. H u s o n 1921. Fate of the lymphocyte. J. Exp. Med., 33 : 593-600.

Davis, B.F. and A. J. Carlson 1909-1910. Contribution to the physiology of lymph. IX. Notes on the lymphocytes in the neck lymph, thoracic lymph, and blood of normal dogs. Amer. J. Physiol., 25 : 173-189.

Goorwit ch, J.H. 1955. Traumatic chylothorax and thoracic duct ligation. Case report and review of literature. J. Thor. Surg., 29: 467-479.

Hanse n, H. G. 1958. Die Physiologie des Lymphozytenwechsels und seine Beeinflussbarkeit durch Hormone des Hypophysen-Adrenalsystems. Georg Thieme, Stuttgart.

Hughes, R., A. J. May and J.G. W id d i combe 1956. The output of lymphocytes from the lymphatic system of the rabbit. J. Physiol., 132: 384-390.

L e e, F.C. 1922. Changes in the number of small lymphocytes of the blood following ligation of the thoracic duct. J. Exp. Med., 36: 247-260.

$\mathrm{M}$ a n n, J.D. and G. M. H ig g in s 1950. Lymphocytes in thoracic duct, intestinal and hepatic lymph. Blood, $5:$ 177-190.

M a u r e r, E. R. 1956. Complete extirpation of thoracic duct. Use in management 
of primary benign tumor producing spontaneous chylothorax. J.A. M. A., 161: 135-138.

Yok oy ama, I., H. Aoki, K. Tatebayashi, T. Hirai, T. Matsumoto and T. F u kushima 1959. Ventriculolymphangiostomy. A shunting operation for hydrocephalus to drain cerebrospinal fluid into the thoracic duct. Fol. psychiat. neurol. jap., 13 : 301-315. 